\title{
Gedenkfeier für Fritz Schaudinn
}

Dem Andenken des 1906 verstorbenen Entdeckers der Syphilisspirochäte Fritz Schaudinn, der damals Regierungsrat im Reichsgesundheitsamt war, gait eine schlichte Feier, die im großen Hörsaal des Zoologischen Instituts der Uni-versität Berlin abgehalten wurde. Dem Festakt wohnten außer der Wit $\lambda$ ve und Mutter des Verewigten eine größere Anzahl von Zool·ogen und Ärzten bei, darunter viele Universitätslehrer. Wie der Direktor des Instituts, Prof. B. Hesse, hervorhob, hat Schaudinn als Schüler von Franz Eilhard Schulze im genannten Institut alle seine hervorragenden Arbeiten ausgeführt, die ihn zu der großen Entdeckung heranreifen ließen und befähigten. Die bahn-brechenden Untersuchungen auf dem Gebiet der Proíozoen- und Parasüenkunde, die Schaudinns zielstrebiger, großer Arbeitskraft zu verdanken sind, würdigte sein Freund Prof. Max Harlmann vom Kaiser-Wilhelms-Institut für Biologie in Dahlem. Schaudinns Mitarbeiter Prof. Erich Hoffmann über-gab alsdann im Namen der gesamten deutschen Ärzteschaft eine von dem kürzlich verstorbenen Dr. Earl Menser hergestellte, auch von der Deutschen Dermatologischen Gesellschaft geförderte Bronze-Wandiafel, die in Schaudinns alten, nunmehr würdig hergerichteten Arbeitszimmer, das als Schau,dinn76

Personalien und Tagesnachrichten.

zimmer eingeweiht wurde, ihren Platz gefunden hat. Die Plakette, die in der Mitte den Kopf Sciiauãinns zeigt, trägt auf der rechten Seite die Widmung der Ärzteschaft und auf der linken einen kurzen Vers: „Dem Forscher, der den Keim entdeckte, - der Liebeslust und Menschensaat - verdarb und tief die Menschheit schreckte, - zum Dank für seine große Tat." Dem "Wunsch von Prof. Hesse und Hoffmann, daß diese Feier den alten unerquicklichen Streit zwischen dem berühmten Franz Eilharä Schulse und seinem genialen Schüíer Fritz Schaudinn durch diesen Akt der Entsühnung und Versöhnung vergessen lassen möge, wird sich die deutsche Ärzteschaft gewiß gern anschließen.

$\mathrm{Da}$ das Sehaudinn-Gedächtníszimmer auch weiterhin der wissenschaft-lichen Arbeit dienen soil, bedeutet eine Ehrung, die der Sinnesart des Ver-ewigten entsprechend ist.

Personalien und Tagesnachrichten.

Prof. Block (Zurich), neben dem Prof. Kreibich, und Jesi,onek zu der früheren Liste (Mulzer, Stühmer, Frieboes) neu genannt waren, hat einen Ruf als Nachfolger des verstorbenen Prof. Arndt an die Universität Berlin erhalten, ebenso Prof. Gans als Nachfolger von Geh. Rat Herxheimer in Frankfurt a. M. und Prof. Schreus als Nachfolger von Prof. Stem an die Hautklinik in Düsseldorf.

Prof. Martenstein (Breslau) wurde zum leitenden Arzt der Hautabteilung des Krankenhauses Friedrichstadt in Dresden gewählt.

Prof. Max Jessner, Oberarzt der Universitäte-Hautklinik in Breslau, ist der bulgarischen Regierung als Beauftragter der Hygiene-Sektion des Völker-bundes der bulgarischen Gesundheitsdirektion zur Organisierung der Syphilis-bekämpfung in Südostbulgarien (Departement Burgas) bis Mitte August zur Verfügung gestellt worden. 
Prof. Levaditi und Dr. Sazerac vom Institut Pasteur in Paris erhielfen den John-Scott-Preis für die Einführung des Wismuts in die Syphilisbehand-lung.

Dr. Fritz Callomon (Dessau) und Dr. Paul Vnna (Hamburg) wurden zu korrespondierenden Mitgliedern der Italienischen Dermatologischen Gesell-schaft erwählt.

Die Witwe des Prof. Louis Brocq hat zum Gedächtnis an ihren verstorbenen Gatten einen Preis gestiftet, der alljährlich für die beste Arbeit auf dem Gebiete der Dermatologie und Syphilidologie verteilt werden soil.

Am '31. 5. und 1.6. fand die gemeinsame Tagung der niederländischen und rheinischwestfälischen Dermatologen in Utrecht an der Kiinik von Prof. van Leeuwen statt, die von sehr zahlreichen Mitgliedern beider Gesellschaften besucht war. Der Vortrag von Prof, nan Leeuwen über die Entstehung der Paget disease, der den Ursprung dieser Erkrankung von dem MammaEpithel begründete, verdient besonders hervorgehoben zu werden. Die Krankenvor-stellungen in der nach englischem Muster trefflich und breit angelegten Poli-klinik, die viele praktisch angeordnete, durch Oberlicht beleuchtete einzelne Untersuchungsräume enthält, waren ausgezeichnet vorbereitet und fanden viel Anerkennung. Diese äritte gemeinsame Tagung hat bewiesen, daß der Ge-danke, die benachbarten Vereinigungen einander näher zu bringen, ein glück-licher gewesen ist.

Am 28. und 29. 6. fand in Dresden eine Tagung der mitteldeutschen, schlesischen und deutschböhmischen Dermatologen statt. Vorträge hielten die Professoren Kreibich (Prag) und Jadassohti (Breslau). 